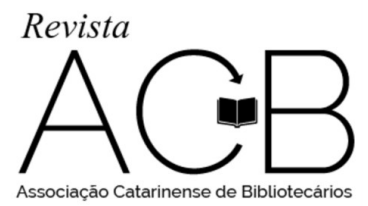

Revista ACB: Biblioteconomia em Santa Catarina, Florianópolis, v. 23, n. 2, p. 322-336, abr./jul., 2018.

\title{
BIBLIOTERAPIA: \\ UMA VIVÊNCIA BIBLIOTERAPÊUTICA DE DESENVOLVIMENTO COM ALUNOS DA DISCIPLINA DE BIBLIOTERAPIA DA UNIVERSIDADE FEDERAL DE SANTA CATARINA (UFSC).
}

\section{Lucas Inacio de Souza ${ }^{1}$ Mônica Elizabeth Yañez Gonzalez ${ }^{2}$ Ana Carolina Sanches ${ }^{3}$}

Resumo: Descreve a atividade de biblioterapia desenvolvida na disciplina de Biblioterapia, ofertada no curso de Biblioteconomia, na Universidade Federal de Santa Catarina (UFSC). Para tal, foi aplicada uma vivência biblioterapêutica de desenvolvimento (Educacional) com a turma de alunos de graduação da UFSC que cursaram a referida disciplina no primeiro semestre de 2018. A atividade constituiu-se de relaxamento com sons da natureza, leitura de história, apresentação de curta-metragem, seguido de atividade lúdica e momento de compartilhamento e diálogo. Conclui-se que os resultados obtidos foram positivos, sendo uma experiência deveras enriquecedora e estimulante/emocionante para a maioria dos participantes na medida em que Ihes permitiu uma reflexão acerca dos benefícios da leitura e dos livros em nossa vida, além de uma interiorização e conscientização do papel de intermediador e bibliotecário na sociedade.

Palavras-chave: Biblioterapia. Biblioterapia de Desenvolvimento (Educacional). Leitura de história.

\section{INTRODUÇÃo}

O que a leitura, os livros, leitura de histórias e a literatura podem fazer na vida de alguém? É notório que as histórias podem ser capazes de nos comover, sensibilizar e até causam outros efeitos benéficos em nossas vidas. A Biblioterapia - no caso deste trabalho, a Biblioterapia de Desenvolvimento, - utiliza textos literários como ferramentas com o intuito de trazer benefícios para as pessoas que a vivenciam, em diversos aspectos e níveis, seja de forma individual ou coletivamente.

Buscando na literatura da área, temos que a Biblioterapia é um conjunto de:

[...] práticas leitoras que utilizam textos-verbais e não-verbais, como coadjuvantes no tratamento de pessoas acometidas por doenças físicas ou mentais ou ainda que

\begin{tabular}{|c|c|c|c|c|c|c|c|c|}
\hline $\begin{array}{l}1 \text { Graduando do Curso de } \\
\text { lucasinaciosouzaata@gmail.com }\end{array}$ & Biblioteconomia & pela & Universidade & Federal & de & Santa & Catarina & (UFSC). \\
\hline $\begin{array}{l}2 \text { Graduanda do Curso de } \\
\text { monicaeyanez@gmail.com }\end{array}$ & Biblioteconomia & pela & Universidade & Federal & de & Santa & Catarina & (UFSC). \\
\hline
\end{tabular}


enfrentam momentos de crise ou dificuldades - exclusão, integração social, afastamento do convívio familiar, de comunicação, etc. a fim de que os sujeitos, por aproximação ou projeção, possam sentir prazer com o texto e assim encontrem respostas para a catarse de seus conflitos, sejam eles físicos, mentais, psicossociais, etc. (BENTES PINTO, et. al., 1995, apud BENTES PINTO, 2005, p. 39)

Biblioterapia pode ser apresentada como auxílio para o tratamento de pessoas acometidas por alguma patologia ou distúrbio (Biblioterapia Clínica), e pode ser utilizada para esse fim, como complemento aos tratamentos convencionais, desde que seja realizado o acompanhamento por médicos ou psicólogos (WITTER, 2004).

No entanto, temos também a Biblioterapia de Desenvolvimento (Educacional), que pode ser aplicada por profissionais previamente capacitados, tais quais bibliotecários, professores, assistentes sociais, dentre outros. Prática a ser desenvolvida em grupos ou individualmente, com finalidades diversas, mas sempre na busca do diálogo depois da história lida ou contadapara tentar trazer benefícios, sejam eles intelectual e/ou social, propiciando bem-estar, reflexão, melhoria de vida, autoconhecimento, etc.

Para Witter (2004, p. 181), a Biblioterapia de Desenvolvimento:

[...] tem por objetivo promover o desenvolvimento do ser humano em aspectos os mais variados que vão do conhecimento de si mesmo ao desenvolvimento de competências e habilidades específicas tais como cidadania, cognição, memória, afetividade, etc.

Todavia, não se perdendo a oportunidade de ser a prática biblioterapêutica um caráter preventivo de pequenos males físicos, cognitivos, psicológicos, entre outros. Segundo Shrodes (1949) e Caldin (2001), os objetivos da biblioterapia estão em torno da verificação de que há mais de uma solução para o problema que a pessoa tem no momento; assim como, da oportunidade de verificação das emoções pessoais em comparação às comparações de outras pessoas; a leitura literária contribui para propor condições por meio de informações consideradas necessárias para se resolver problemas e para encorajar o leitor a encarar sua situação de forma realista de forma, sendo conduzido à ação. 


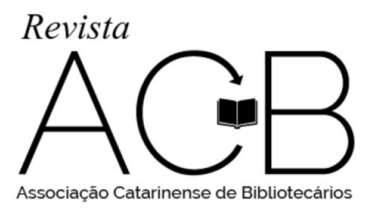

Revista ACB: Biblioteconomia em Santa Catarina, Florianópolis, v. 23, n. 2, p. 322-336, abr./jul., 2018.

O objetivo geral do trabalho proposto foi o de aplicar uma vivência da atividade biblioterapêutica com o grupo de alunos da disciplina de Biblioterapia da UFSC, buscando o bemestar e a interiorização (individual e/ou grupal) da importância da Biblioterapia, proporcionando uma reflexão sobre o papel social do bibliotecário na sociedade atual.

Os objetivos específicos ficaram assim dispostos: analisar as informações levantadas por meio dos registros escritos pelos participantes; conhecer o impacto da aplicação da atividade biblioterapêutica; classificar os resultados de acordo com a percepção e exteriorização oral dos participantes.

Acredita-se que a aplicação da biblioterapia pode ser um meio para diminuir ou mesmo sanar, porventura algum estresse, proporcionando e promovendo aos participantes da prática, um sentimento de bem-estar, mesmo que temporário.

\section{A APLICAÇÃO DA BIBLIOTERAPIA}

A aplicação da atividade biblioterapêutica aconteceu na UFSC, sendo esta uma instituição de ensino superior de caráter público e gratuito, e referência em Ensino, Pesquisa e Extensão no Brasil. Sua comunidade é constituída por cerca de 60 mil pessoas, entre docentes, técnicosadministrativos em educação e estudantes de graduação, pós-graduação, ensino médio, fundamental e básico (UNIVERSIDADE FEDERAL DE SANTA CATARINA, 2018).

Esclarecemos que a atividade ocorreu em uma sala de aula, localizada no $2^{\circ}$ andar do Bloco D, do Centro de Ciências da Educação (CED), no Campus da UFSC no Bairro Trindade, em Florianópolis-SC, no dia 4 de junho de 2018, às 18 h30.

Foram dispostas as mesas e as cadeiras em círculo, de modo que todos pudessem ficar de frente uns para os outros e pudessem também enxergar tanto a televisão, quanto a leitora da história.

A equipe que elaborou, planejou, fez a aplicação da vivência biblioterapêutica contava com três pessoas, sendo os componentes os autores deste trabalho, e mais uma pessoa para suporte, caso ocorresse algum imprevisto, sendo esta o doutorando em estágio docência do Programa de 


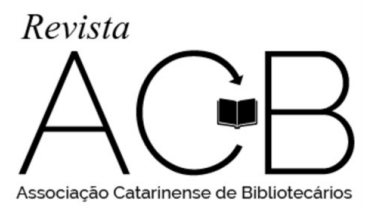

Revista ACB: Biblioteconomia em Santa Catarina, Florianópolis, v. 23, n. 2, p. 322-336, abr./jul., 2018.

Pós-Graduação em Ciência da Informação da UFSC, que conjuntamente com a professora responsável pela disciplina ministraram-na.

Poderiam participar da vivência, os estudantes de graduação da UFSC, que estavam matriculados na disciplina Biblioterapia do primeiro semestre de 2018, sendo 2 pessoas do curso de Letras; 1 pessoa do curso de Antropologia; 1 pessoa do Curso de História; 2 pessoas do Curso de Arquivologia, e; 9 pessoas do Curso de Biblioteconomia.

No momento da aplicação, do total de alunos matriculados na disciplina, 13 estavam presentes e demonstraram interesse em participar, comparecendo no dia e na hora marcados para a aplicação, contando ainda com a participação do professor da disciplina para dar suporte e tratar com imprevistos e a Biblioterapeuta convidada como participante experimentadora da vivência em Biblioterapia, Liège Knoche.

\section{A PRÁTICA}

O desenvolvimento da prática biblioterapêutica teve seu início quando a porta da sala foi aberta às 18h20min e os aplicadores recepcionaram os alunos e os demais participantes. A recepção orientou para que todos escolhessem um lugar nas mesas com cadeiras e para que assinassem o Termo de Consentimento Livre e Esclarecido (TCLE). Todos foram acomodados, e às 18 h30 deu-se então início à atividade.

Houve uma breve apresentação da equipe de aplicadores da biblioterapia, e, em seguida, os participantes da atividade foram informados que utilizassem a folha sulfite colorida disposta em cada mesa para fazer anotações, desenhos, etc., caso se sentissem confortáveis em fazê-lo e que a mesma folha seria recolhida no final da atividade.

Também foram informados que a atividade biblioterapêutica estaria sendo documentada, fotografada (Apêndice) e gravada na forma de áudio, para composição do relatório da coleta de dados a ser analisado e apresentados em resultados da pesquisa, e por isso a necessidade da assinatura no TCLE. 


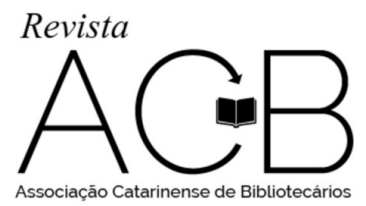

Revista ACB: Biblioteconomia em Santa Catarina, Florianópolis, v. 23, n. 2, p. 322-336, abr./jul., 2018.

A atividade foi separada em quatro momentos distintos: 1) sessão de relaxamento; 2) leitura de história; 3) apresentação de curta-metragem; 4) atividade lúdica, seguida de momento de compartilhamento e diálogo.

\section{Momento 1 - Relaxamento - Tempo: 6 minutos}

As luzes foram apagadas e com auxílio de uma caixa de som foram colocados sons relaxantes, de florestas, de pássaros e de riacho de água corrente. Com a voz, o locutor ia guiando os movimentos de relaxamento e respiração de todos.

Parte da atividade solicitava aos participantes que fechassem os olhos, procurando sempre relaxar, controlando a respiração, com movimentos de inspiração e expiração, fazendo a mente imaginar que estavam presentes em um ambiente natural e acolhedor.

Esses procedimentos, além de relaxar, aliviar o stress e preocupações que os participantes poderiam estar acumulando, ajudaram a acalmar da correria do dia-a-dia e, também, a "limpar" a mente para melhor absorver a história e o restante da atividade.

\section{Momento 2 -Leitura de História - Tempo: 5 minutos}

Nessa etapa, a aplicadora Mónica Elizabeth Yañez Gonzalez procedeu com a leitura do livro referenciado a seguir:

JOYCE, Willian. Os Fantásticos Livros Voadores de Modesto Máximo. [tradução Elvira Vigna]. Rio de Janeiro: Rocco, 2012.

Ilustração 1: Os fantásticos livros voadores de Modesto Máximo.

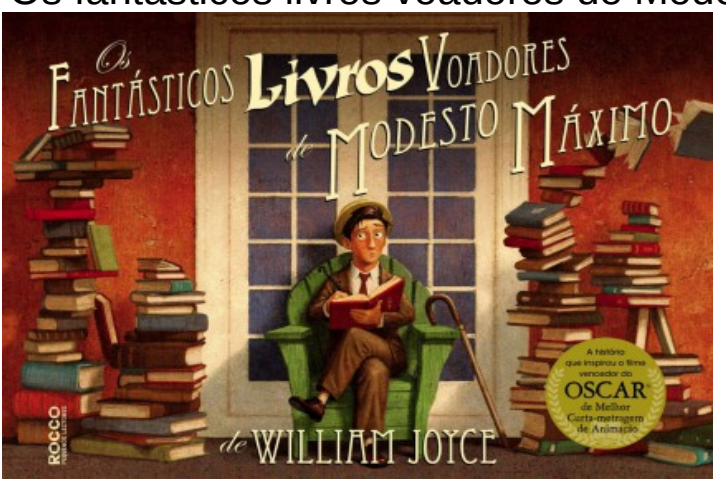

Fonte: Disponível em: <https://statics.livrariacultura.net.br/products/capas_lg/475/30362475.jpg>. Acesso em: 12 abr. 2018. 


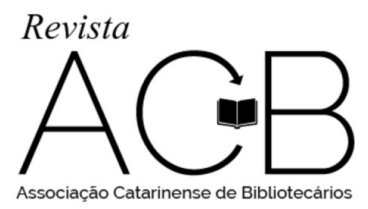

Revista ACB: Biblioteconomia em Santa Catarina, Florianópolis, v. 23, n. 2, p. 322-336, abr./jul., 2018.

O livro destaca o poder dos livros sobre os leitores e como podem mostrar-lhes novos mundos, caminhos e direções, além daquelas a que estão acostumados ou habituados a seguir.

Resumindo a história conta como o Sr. Modesto Máximo (Morris Lessmore em inglês) é arrastado para um mundo onde os livros são vivos, e cada um deles oferece uma viagem à parte para o leitor navegar em suas páginas. O personagem encontra a paixão pela leitura, e o Sr. Modesto Máximo passa a viver nesse mundo dos livros vivos. Desta feita, a destruição ao seu redor ganha cor, sendo a devastação passada a ser vista por um viés não tão essencial quanto a viagem maravilhosa que a literatura lhe proporciona, inclusive através do prazer de escrever. Assim, o Sr. Modesto Máximo perde todo seu bem material, mas prevalece a esperança para seguir sua jornada. Ele consegue se reestruturar e ajuda outras pessoas moradoras da cidade destruída, a contribuição para eles vem dos livros e das leituras de histórias.

Durante a leitura da história, eram exibidos, na televisão, os slides com as imagens retiradas do livro, a fim de ilustrar a história. A mesma não foi contada inteira, somente metade foi lida, aguçando a curiosidade dos participantes para saber o final.

\section{Momento 3 - Apresentação de Curta-Metragem - Tempo: 15 minutos}

Em seguida, com o auxílio de uma televisão, foi exibido o curta-metragem "Os Fantásticos Livros Voadores do Sr. Morris Lessmore", ganhador do Oscar de melhor curta metragem de Animação no ano de 2012.

Quadro 1 - Dados técnicos do filme.

Título original: The Fantastic Flying Books of Mr. Morris Lessmore

Direção: William Joyce / Brandon Oldenburg

Roteiro: William Joyce

Gênero: Animação / Aventura / Drama

Origem: Estados Unidos

Ano de produção: 2011

Duração: 15 Minutos

Fonte:Diponível em: <http://www.nossomundoliterario.com.br/2014/07/curta-os-fantasticos-livrosvoadores-do.html>. Acesso em: 07 mar. 2018. 


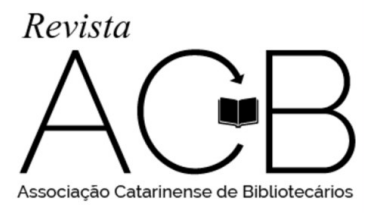

Revista ACB: Biblioteconomia em Santa Catarina, Florianópolis, v. 23, n. 2, p. 322-336, abr./jul., 2018.

\section{Momento 4 - Atividade lúdica e discussão orientada - tempo: 5 a 10 minutos}

Nessa etapa, sob orientação dos aplicadores da biblioterapia, foi dado um tempo estipulado pela equipe para que cada um dos participantes rabiscasse, desenhasse, ou escrevesse versos, frases, algo relacionado à história ou sobre o que sentiram ao conhecer o enredo, utilizando a folha sulfite colorida.

Esse recurso foi utilizado para que fosse possível encorajar aquelas pessoas mais tímidas a escreverem seus sentimentos, suas percepções, ou outras formas de provocação que o texto possa ter feito em cada uma delas. Assim, no momento de compartilhar e dialogar, expondo suas ideias e opiniões, as pessoas pudessem recorrer ao papel para ler ou comentar sobre as anotações que já estavam elas elaboradas no papel.

Passados em torno de cinco minutos, foi aberta a palavra a todos os participantes que queriam, de alguma forma, dizer algo a respeito da história, ou mesmo ler/mostrar o que rabiscou no papel, mostrando o entendimento pessoal da história, ou sentimentos, inspirações, etc.

A discussão do grupo ficou livre, participou da fala quem se sentiu à vontade para fazer. No entanto, os aplicadores ficaram sempre na condução e mediação para que as conversas voltassem para a temática do texto e da aplicação de biblioterapia, dentre as quais: o encantamento da leitura na nossa vida; sensações de bem-estar ou outros sentimentos vivenciados; interiorização (individual e/ou grupal) da importância da Biblioterapia; reflexão sobre nosso papel social na sociedade atual como profissionais da informação ou outras profissões.

\section{Encerramento - Café e entrega de lembrancinha}

Finda a atividade, houve agradecimento pela participação de todos e foi entregue uma lembrancinha aos participantes (marcador de página artesanal) e, com a intenção de aquecer e confraternizar, uma das integrantes do grupo da aplicação da atividade levou uma garrafa térmica e foi oferecido um café. A mesma integrante da aplicação elaborou as lembrancinhas para o grupo de alunos da disciplina. 


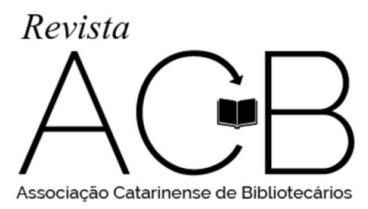

Revista ACB: Biblioteconomia em Santa Catarina, Florianópolis, v. 23, n. 2, p. 322-336, abr./jul., 2018.

\section{RESULTADOS OBTIDOS}

Aplicou-se a vivência da atividade biblioterapêutica com o grupo de alunos da disciplina de Biblioterapia da UFSC e com isso proporcionou-se aos alunos um momento de bem-estar e interiorização que resultou em reflexões grupais e individuais.

Os pontos fortes da ação foram a coordenação, a dinâmica e a interação dos integrantes da equipe com os participantes, possibilitando êxito em todas as etapas, desde a recepção aos alunos, passando por todos os momentos, não havendo interrupções ou atrasos, iniciando e terminando a atividade no horário previsto.

Por ser uma atividade nunca vivenciada pelos aplicadores, os fatores de maior dificuldade foram a ansiedade e o nervosismo, devidos à expectativa de que todos os objetivos fossem atingidos, ou seja, todas as etapas da atividade de vivência biblioterapêutica fossem cumpridas.

Foi uma atividade planejada e orientada em todas as etapas. Portanto, podemos afirmar que se cumpriram todos os objetivos, bem como foram alcançados os resultados positivos pretendidos.

Sobre o relaxamento, houve um consenso de que sua aplicação ajudou a relaxar e até mesmo temos os depoimentos de que auxiliou para produzir um pouco de calma na correria do dia-a-dia, desacelerando e preparando a mente para receber a história e, com a leitura, foram levados ao universo mágico contido no texto.

Houve receptividade da história pelos participantes, tanto na modalidade leitora da história, quanto na modalidade da apresentação do curta-metragem e, mesmo alguns relatando já conhecê-la, ainda assim, não houve comentários negativos ou depreciativos. O momento da leitura, em tom calmo e pausado, os manteve concentrados levando-os à uma interiorização de sentimentos e de reflexão, emoção e nostalgia. Segundo relatos orais durante o desenvolvimento da prática de biblioterapia e de acordo com trechos escritos nas folhas disponibilizadas.

Dos 13 participantes, somente duas não quiseram fazer relatos orais, porém, apesar da timidez, todos transcreveram suas reflexões acerca da história na atividade lúdica.

Foram relatadas nas folhas coloridas e apontadas oralmente as reflexões durante a discussão orientada acerca do valor dos livros, da valorização da leitura, da tempestade 


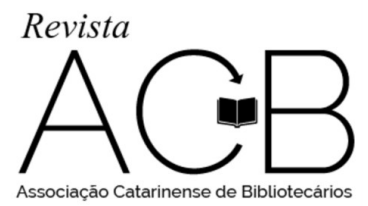

Revista ACB: Biblioteconomia em Santa Catarina, Florianópolis, v. 23, n. 2, p. 322-336, abr./jul., 2018.

(coadjuvante na história) em que o personagem acaba perdendo tudo, e mesmo assim não perde a esperança e segue em frente, conseguindo se reestruturar (e voltar ao colorido anterior) e ainda ajudar e dar vida (cor) aos demais personagens moradores da cidade destruída através dos livros e leitura,inclusive alguns apontamentos sobre a importância e responsabilidade do profissional bibliotecário.

Os sentimentos relatados foram os mais variados: alegria, entusiasmo, encantamento com a história, empatia e identificação pelo personagem, melancolia, tristeza, dor pela perda (morte), emoção, comoção e até lágrimas.

Como contribuições da ação ficam as reflexões sobre o poder que o livro tem de trazer encantamento a cada um, em cada história, além de conhecimentos relativos à vida e leitura, cabendo também a questão do acesso à leitura, sendo lembrado por alguns participantes que muitos cidadãos brasileiros ainda são analfabetos. E ficou também a reflexão de nosso papel como bibliotecários em cuidar e preservar os livros, mas também garantir o acesso à leitura.

\section{CONCLUSÕES}

Podemos, enquanto equipe, refletir e afirmar que nosso objetivo de aplicar a vivência da atividade biblioterapêutica com o grupo de alunos da disciplina de Biblioterapia da UFSC, com a finalidade de promover o bem-estar e a interiorização (individual e/ou grupal) da importância da Biblioterapia foi alcançado. Assim como o interesse em ter um contato maior com a parte prática da disciplina. Oportunidade esta que nos permitiu reafirmar a importância da biblioterapia, inclusive no tocante ao fortalecimento da capacidade imaginativa e interpretativa. A prática nos fez refletir sobre a leitura e sua capacidade de propiciar benefícios à vida humana.

Por meio do diálogo e da interpretação, foi possível trazer para o grupo a reflexão sobre o papel social do bibliotecário na sociedade atual, sendo ele um mediador de textos que possibilitam a discussão de temáticas pertinentes a problemas sociais e permitindo o diálogo acerca dos assuntos encontrados nos textos.

Todo o delineamento do procedimento de desenvolver a prática de biblioterapia foi executado com sucesso, o que nos permitiu analisar as informações dos registros provenientes da 


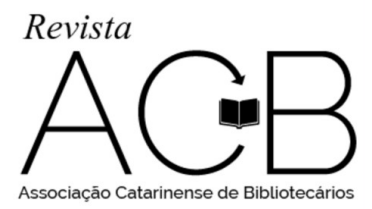

Revista ACB: Biblioteconomia em Santa Catarina, Florianópolis, v. 23, n. 2, p. 322-336, abr./jul., 2018.

vivência e buscar conhecer quais são os impactos causados nos participantes da atividade biblioterapêutica, momento de exteriorização do efeito da literatura sobre os ouvintes.

Consideramos a biblioterapia de suma importância e a sua aplicação, quando bem executada, torna-se um meio que possibilita a abertura para o diálogo e discussão de problemas em diversas esferas sociais.

Dentre os já citados benefícios da aplicação da biblioterapia, e de acordo com nossa percepção, ficou evidente o seu uso como ferramenta para diminuir o estresse e trazer o sentimento de bem-estar, mesmo que temporário, aos participantes, o que se demonstrou com os registros dos depoimentos dos mesmos.

"A leitura de um bom livro é um diálogo incessante: o livro fala, e a alma responde". (André Maurois).

\section{Agradecimentos}

Agradecemos à professora da disciplina, Marli Dias de Souza Pinto, por disponibilizar a disciplina de Biblioterapia em parceria com Evandro Jair Duarte, doutorando em Ciência da Informação pelo Programa de Pós-Graduação em Ciência da Informação (PGCIN/UFSC), a quem agradecemos por ministrar aulas e auxiliar-nos com o projeto, a prática e a escrita deste texto.

\section{REFERÊNCIAS}

CALDIN, Clarice Fortkamp. A leitura como função terapêutica: biblioterapia. Enc. Bibli: R. Eletr. Bibliotecon. Ci. Inf., v. 6, n. 12, p. 32-44, 2001.

PINTO, Virginia Bentes. A biblioterapia como campo de atuação para o bibliotecário.Transinformação, vol.17, n. 1, p. 31-43, jan-abr, 2005.

UNIVERSIDADE FEDERAL DE SANTA CATARINA. Estrutura. 2018. Disponível em: <https://estrutura.ufsc.br>. Acesso em: 12 jun. 2018.

WITTER, Geraldina Porto. Biblioterapia: desenvolvimento e clínica. In: Leitura e Psicologia. Campinas: Alinea, 2004. 


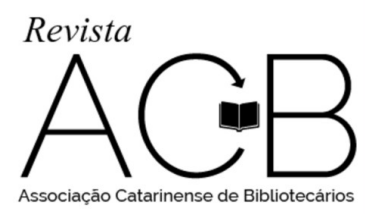

Revista ACB: Biblioteconomia em Santa Catarina, Florianópolis, v. 23, n. 2, p. 322-336, abr./jul., 2018.

\section{APÊNDICES}

Imagem 1 - Momento um - Relaxamento.

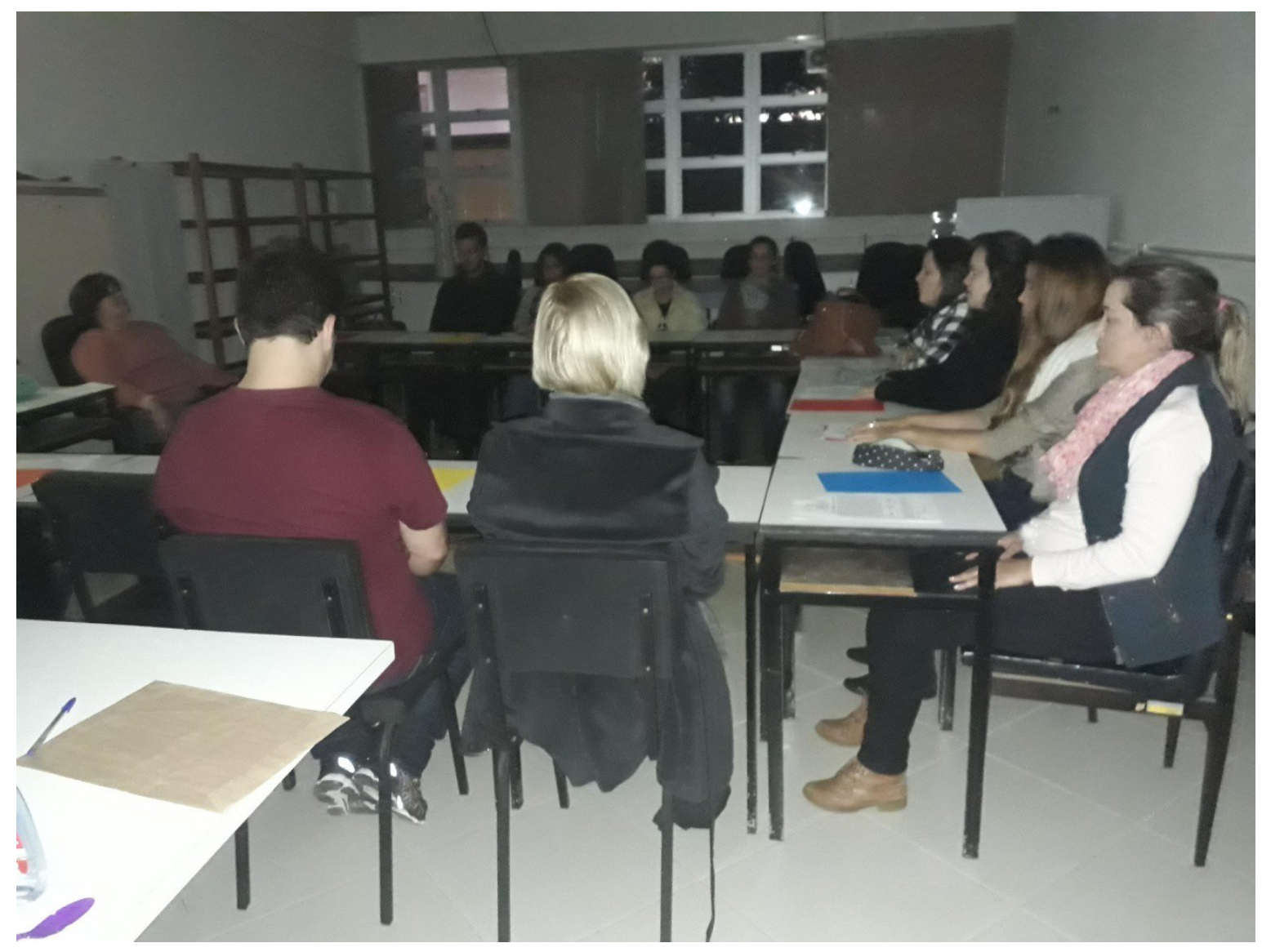

Fonte: Dos autores (2018). 


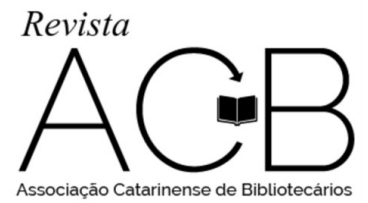

Revista ACB: Biblioteconomia em Santa Catarina, Florianópolis, v. 23, n. 2, p. 322-336, abr./jul., 2018.

Imagem 2 - Momento dois - Leitura de História. 


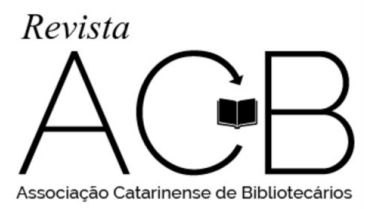

Revista ACB: Biblioteconomia em Santa Catarina, Florianópolis, v. 23, n. 2, p. 322-336, abr./jul., 2018.

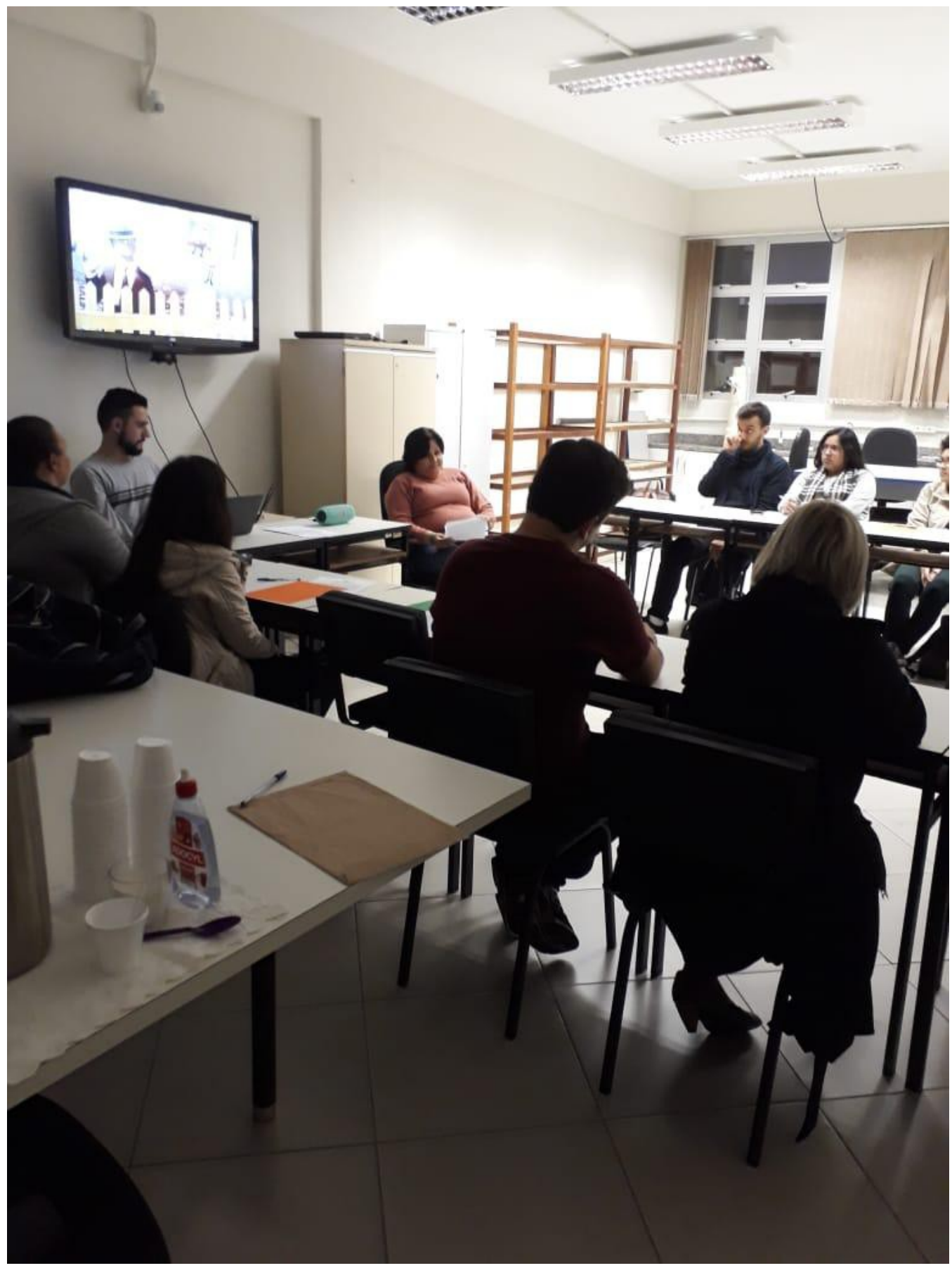

Fonte: Dos autores (2018).

Imagem 3 - Momento três - Apresentação do curta-metragem de 15 minutos. 


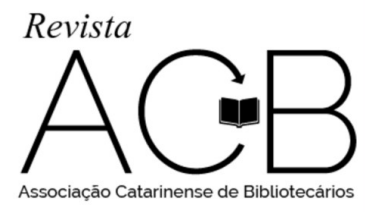

Revista ACB: Biblioteconomia em Santa Catarina, Florianópolis, v. 23, n. 2, p. 322-336, abr./jul., 2018.

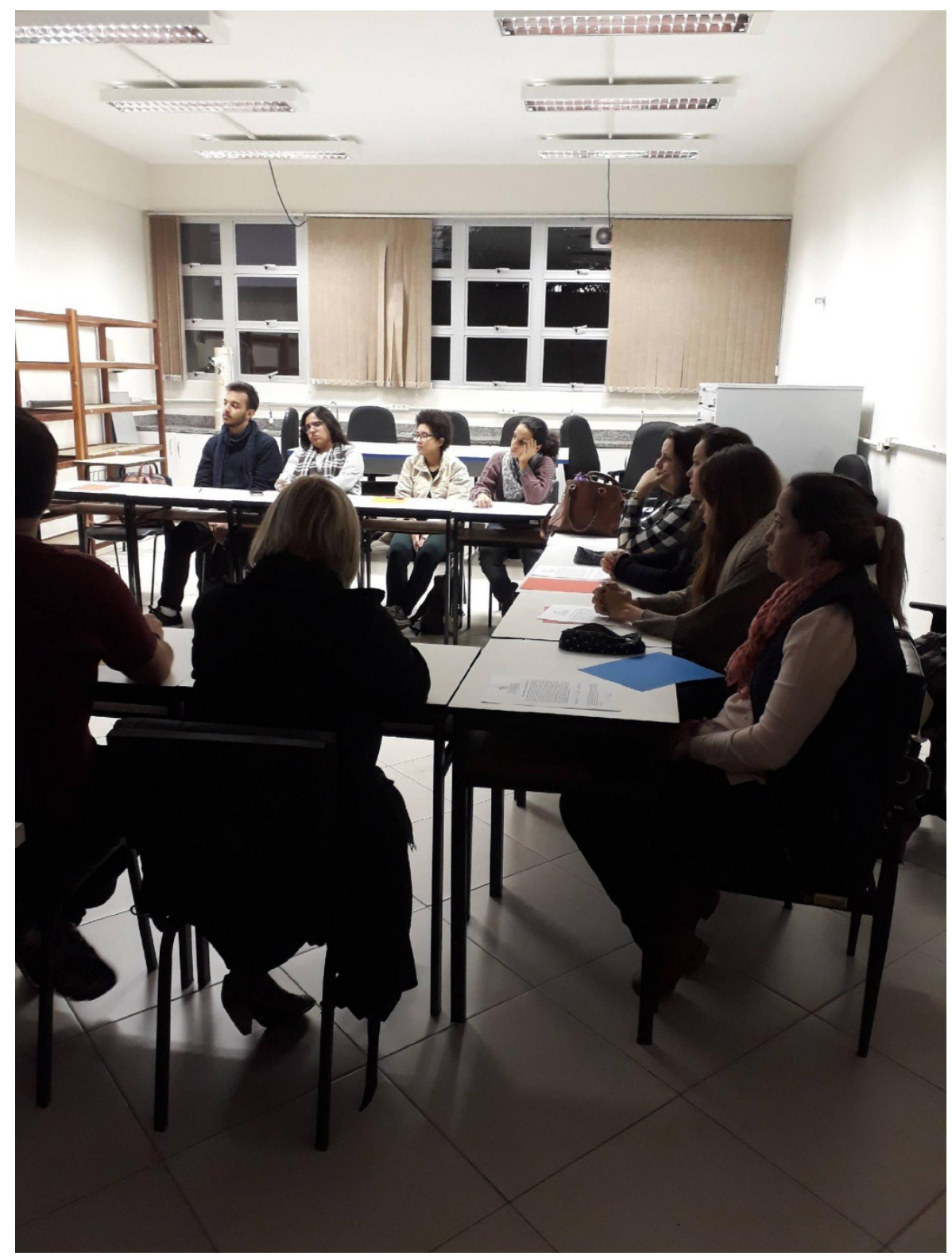

Imagem 4 - Momento quatro - Atividade lúdica e discussão orientada. 


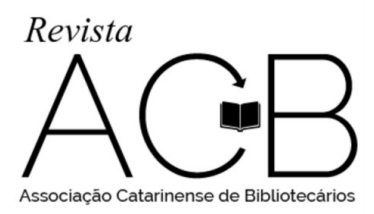

Revista ACB: Biblioteconomia em Santa Catarina, Florianópolis, v. 23, n. 2, p. 322-336, abr.jjul., 2018.

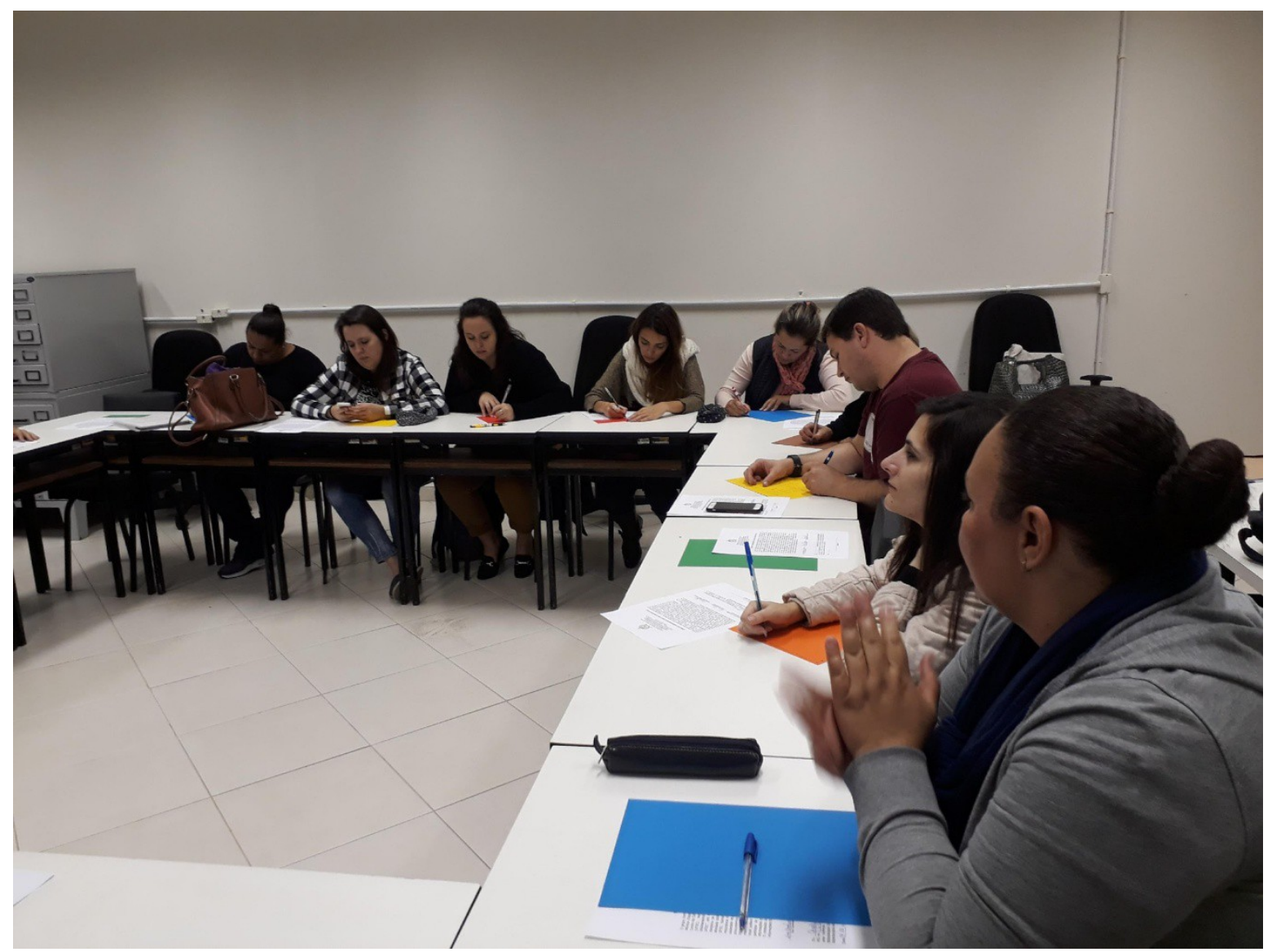

Fonte: Dos autores (2018). 


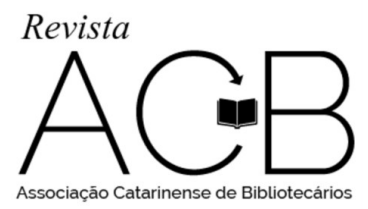

Revista ACB: Biblioteconomia em Santa Catarina, Florianópolis, v. 23, n. 2, p. 322-336, abr./jul., 2018.

\section{BIBLIOTHERAPY: \\ A BIBLIOTHERAPEUTIC DEVELOPMENT LIVING WITH STUDENTS OF THE BIBLIOTHERAPY DISCIPLINE OF THE FEDERAL UNIVERSITY OF SANTA CATARINA (UFSC).}

Abstract: Describes the activity of bibliotherapy developed in the discipline of Biblioterapia, offered in the course of Librarianship, at the Federal University of Santa Catarina (UFSC). To that end, a bibliotherapy experiment was applied (Educational) with the group of UFSC undergraduates who attended the course in the first semester of 2018. The activity consisted of relaxation with sounds of nature, reading of history, presentation of short film, followed by ludic activity and moment of sharing and dialogue. It was concluded that the results were positive and a very enriching and stimulating / exciting experience for the majority of participants, as it allowed them to reflect on the benefits of reading and books in our lives, as well as an interiorization and awareness the role of intermediary and librarian in society.

Keywords: Bibliotherapy. Bibliotherapy of development (Educational). History reading.

RECEBIDO: $17-07-2018$

ACEITO: 21-07-2018 